\title{
AVALIAÇÃO DO POTENCIAL DE CORROSÃO EM CONCRETOS DE ALTO DESEMPENHO COM AGREGADO LEVE
}

\author{
OLIVEIRA, GABRIEL YVES DA SILVA \\ Estudante \\ Universidade Católica de Brasília \\ Distrito Federal; Brasil \\ gabriel.yves87@gmail.com \\ CAETANO, RAFAEL NOGUEIRA \\ Estudante \\ Universidade Católica de Brasília \\ Distrito Federal; Brasil \\ rafaeln.caetano@gmail.com
}

\author{
SOUZA, GUILHERME PEREIRA DE \\ Estudante \\ Universidade Católica de Brasília \\ Distrito Federal; Brasil \\ guilhermeucbpsouza@gmail.com
}

\author{
SILVA, MAYKON VIEIRA \\ Engenheiro Civil \\ Universidade Católica de Brasília \\ Distrito Federal; Brasil \\ eng.maykonsilva@gmail.com
}

\section{RESUMO}

Este trabalho tem como objetivo a análise de corrosão em estruturas de concreto armado que utilizam concreto leve de alto desempenho (CLAD), haja visto que, a corrosão é uma das principais manifestações patológicas em estruturas de concreto armado, ocasionando o desplacamento do concreto e a corrosão do aço. Foram moldados corpos de prova, de traços: convenional e com agregado leve (argila expandida), ambos de alto desempenho, moldados, curados e rompidos nos intervalos de dias conforme a norma NBR 5739 (ABNT, 2018). A partir do valor de resistência à compressão dos corpos de prova, moldados com argila expandida, e com suas respectivas massas específicas seca, foram obtidos os valores dos Fatores de eficência $(\mathrm{Fc})$, para a verificação se o traço utilizado poderia ser classificado como concreto leve de alto desempenho, que foi o que ocorreu. Para o ensaio de potencial de corrosão o texto baseou-se na norma ASTM C876 (1999), onde o mesmo pôde ser obtido através de uma diferença de potencial exercida sob uma meia célula com barra de cobre maciça imersa em meio aquoso com sulfato de cobre. Foram feitas peças prismáticas em formato retangular, moldados a partir do concreto de alto desempenho: convencional (CAD) e com argila expandida (CLAD), que foram submetidas à um ambiente agressivo, com iminente corrosão, através de uma solução de cloreto de sódio, e posteriormente levada a estufa. Após alguns ciclos de esposição ao ambiente e secagem, constatou-se que as peças de CLAD e CAD obtiveram valores de potencial de corrosão extremamente próximos, não sendo possível, a determinação de qual obteve um melhor desempenho nesta avaliação.

Palavras-chave: concreto leve, corrosão, alto desempenho.

\section{ABSTRACT}

This work has as objective the analysis of corrosion in reinforced concrete structures that use high performance lightweight concrete (HPLC), considering that corrosion is one of the main pathological manifestations in reinforced concrete structures causing the concrete peeling and corrosion of steel. Specimens were molded with the following features: conventional and lightweight aggregate (expanded clay), both high performances, molded, cured and ruptured at day intervals according to NBR 5739 (ABNT, 2018). From the compressive strength value of the expanded clay molded specimens and their respective dry specific masses, the Efficiency factor (Ef) values were obtained to verify whether the trace used could be classified as high performance lightweight concrete, which is what happened. For the corrosion potential test the text was based on ASTM C876 (1999), where it can be obtained by a potential difference exerted under a solid copper bar half-cell immersed in aqueous medium with copper sulfate. Prismatic rectangular pieces have been made from high performance concrete: conventional (HPC) and expanded clay (HPLC) were made and subjected to an aggressive environment with imminent corrosion through a solution of sodium chloride. And later then take to the kiln. After few cycles of exposure to the environment and drying, it was found that the parts of HPLC and HPC obtained values of corrosion potential extremely similar. Therefore, the determination of which one (HPLC or HPC) obtained a better performance, couldn't be asserted.

Keywords: lightweight concrete, corrosion, high performance. 


\section{INTRODUÇÃO}

A aplicação dos concretos com agregados leves data de 1100 a.C., no México. Também se tem conhecimento histórico de 273 a.C., no Porto de Cosa, na Europa, sobre estruturas em concreto leve que resistiram às ações da natureza por mais de dois mil anos (ROSSIGNOLO, 2009).

A partir de 1980, foram realizadas rigorosas pesquisas sobre os concretos leves, em todo o mundo, demonstrando o grande potencial do uso desse material, nas mais diversas áreas da construção civil. A redução da massa específica do concreto, com a manutenção da resistência mecânica, propicia a redução do peso próprio e das cargas na fundação, com conseqüente redução do custo final da obra. (SLATE et al., 1986; MORENO, 1986; BERNER, 1991; ZHANG e GJ $\phi R V$, 1991a; HOLM e BREMNER, 1994; IKEDA, 2000; VIEIRA e GONÇALVES, 2000; ROSSIGNOLO et al., 2001)

De acordo com Metha e Monteiro (1994), os agregados com massa unitária inferior a $1120 \mathrm{~kg} / \mathrm{m}^{3}$ são considerados leves, e têm aplicação na produção de diversos tipos de concretos leves. Conseguem-se agregados leves naturais através do beneficiamento de rochas ígneas vulcânicas como pumicita, escória ou tufo. Por outro lado, os agregados leves industrializados podem ser fabricados por tratamento térmico de uma variedade de materiais, por exemplo, argilas, folhelhos, ardósia, diatomita, perlita, vermiculita, escoria de alto forno e cinza volante.

No caso dos concretos leves, os agregados podem apresentar grande influência na permeabilidade dos concretos, caso apresentem a estrutura porosa comunicante, pois este fato facilita o fluxo de líquido e gases e consequentemente de agentes agressivos no concreto. Alguns agregados leves, como a argila expandida, apesar de apresentarem valores de porosidade acima de 50\%, apresentam baixa permeabilidade, pois a grande maioria dos poros não são interligados, não criando, assim, caminhos preferenciais (HOLM e BRENMER, 1994; SOBRAL, 1996).

Segundo Zhang e Gj申rv (1990a, 1990b) e Wasserman e Bentur (1996), a interface entre o agregado leve e a matriz de cimento apresenta baixa porosidade e caracteriza-se pela alta ancoragem mecânica entre os dois, consequência da rugosidade da superfície do agregado. Os agregados leves produzidos em forno rotativo utilizando argila (argila expandida), não apresentam potencial de reação pozolânica com a matriz de cimento.

Nas duas últimas décadas, a tecnologia do concreto sofreu um grande desenvolvimento que, segundo diversos pesquisadores, como Zhang e Gjprv (1991a), Almeida (1996), Paulon (1996), Ohama (1998), Helene (1999) e Aïtcin (1999), ocorreram devido à evolução das técnicas e equipamentos para estudo dos concretos e ao uso de novos materiais. Estes novos materiais, dentre os quais destacam- se os aditivos redutores de água e as adições minerais possibilitaram melhorias significativas nas propriedades relacionadas à resistência mecânica e à durabilidade dos concretos. Dentre as novas técnicas de estudo dos concretos, destacamse as técnicas de estudos microestruturais, que permitiram o conhecimento aprofundado da microestrutura da matriz de cimento e da zona de transição entre o agregado e a matriz de cimento.

O desenvolvimento de novos materiais e técnicas de estudos resultou em um incremento da utilização dos concretos especiais, principalmente os concretos de alto desempenho (CAD). Sisel (2000) afirma que, atualmente, o conceito mais moderno de construção de edifícios de grande altura, em todo o mundo, é aquele que utiliza, conjuntamente, as tecnologias do CAD e do aço. Nos últimos anos, algumas pesquisas foram realizadas com o intuito de aperfeiçoar, ainda mais, as propriedades dos concretos de alto desempenho. Dentre elas, duas linhas de estudo se destacam: a união das características aperfeiçoadas do CAD com a baixa massa específica dos concretos leves estruturais (CLE), obtendo-se, assim, o concreto leve de alto desempenho (CLAD).

Segundo Alduaij et al. (1999) e Haque e Al-Khaiat (1999), existe uma tendência mundial crescente, baseada em critérios econômicos e técnicos, do uso do CLAD com finalidade estrutural e de vedação na construção civil, especialmente com a utilização da tecnologia dos pré-fabricados.

Atualmente, o CLAD é definido através de um parâmetro que relaciona resistência à compressão e massa específica seca do material. Essa relação é denominada de fator de eficiência (Holm e Bremner, 1994), sendo considerado como concreto leve de alto desempenho um concreto com fator de eficiência acima de $25 \mathrm{MPa} . \mathrm{dm}^{3} / \mathrm{kg}$. Este é um parâmetro importante, especialmente para projetos em que o peso da estrutura tem bastante influência nas cargas permanentes, sendo que os concretos leves apresentam esse valor maior para este parâmetro do que os convencionais (ROSSIGNOLO; OLIVEIRA, 2007).

Assim como em estruturas de concreto convencionais, no CLAD, também haverá a presença de problemas patológicos relacionados à corrosão das armaduras de aço-carbono no concreto leve de alta resistência, principalmente nas regiões litorâneas do país. Esta corrosão é, principalmente, consequência do efeito do ambiente de exposição, como exemplo, a exposição à atmosfera rica em dióxido de carbono e ou à névoa salina (íons cloreto). Outros fatores relacionados à corrosão seriam: as características dos materiais empregados, as solicitações que as estruturas estão sujeitas ao longo dos anos de sua utilização e as usuais restrições de manutenções periódicas.

A presença de dióxido de carbono no concreto resulta na diminuição do $\mathrm{pH}$ da solução aquosa de poros do concreto para valores em torno de 9. Esse fenômeno é chamado de carbonatação e o seu avanço no concreto de cobrimento da armadura resulta na perda, generalizada, do filme de óxidos que mantém a armadura passivada.

Notoriamente há uma grande preocupação com a presença dos íons cloreto (Cl-) na solução aquosa dos poros do concreto. Isso porque, esses íons quebram localmente o filme passivante, tendo-se a formação de pequenas cavidades, denominadas de pites. Com o avanço do ataque, a corrosão se generaliza, devido ao coalescimento dos pites já formados. As pesquisas mostram que a 
despassivação do filme na presença de íons cloreto é dependente da sua concentração e da relação com os íons hidroxila (OH-) também presentes na solução aquosa de poros.

No presente trabalho, serão apresentados resultados da avaliação da corrosão de armaduras de corpos de prova de CLAD e de CAD. A avaliação contemplou a realização de inspeções por meio de ensaios de laboratório das peças prismáticas preparadas, baseados na norma americana ASTM C876 (1999), além da execução de corpos de prova moldados conforme a NBR 5738 (ABNT, 2015), afim de obter resultados que evidenciassem o fator de eficiência do CLAD.

\section{METODOLOGIA}

\subsection{Execução das estruturas prismáticas de base quadrada}

Primeiramente, foram separadas barras de aço CA-50 de $16 \mathrm{~cm}$ de comprimento por $10 \mathrm{~mm}$ de diâmetro cujo estado físicoquímico teve de ser reparado de modo a apresentar resultados livres de quaisquer interferências por parte do material utilizado. Deste modo, o preparo procedeu conforme norma técnica americana ASTM G1 (1990) prescreve, e para tanto foi realizada a limpeza destas barras com solução de ácido clorídrico $(\mathrm{HCl})$ na proporção de 1:1 e hexametilenotetramina (C6H12N4) na quantidade de $3,5 \mathrm{~g} / \mathrm{dm}^{3}$ e assim deixada imersa pelo período de 15 minutos.

Posterior a esta etapa, as barras foram lavadas com escovas de cerda e sabão, afim de evitar ademais oxidações externas, e assim, mergulhadas em acetona por três minutos visando secagem mais rápida. Após estarem todas secas, foram todas embaladas separadamente em plástico filme e armazenadas para continuidade do procedimento.

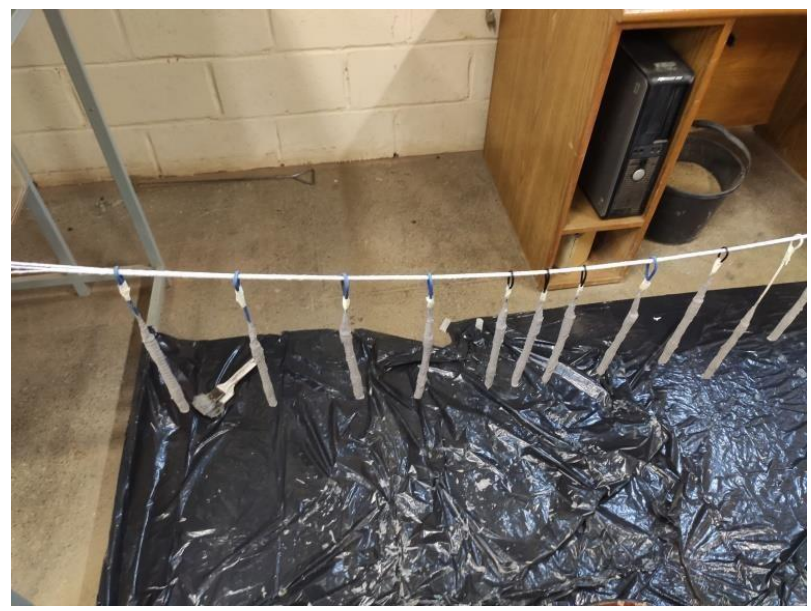

Figura 1 - Barras de aço CA-50 em secagem.

Acoplado à barra, fios de cobre foram colocados e desencapados em suas extremidades para que a leitura de corrosão desta pudesse ser realizada, e por fim, mistura entre resina e cola epóxi visando junção dos elementos, com aplicação de $3 \mathrm{~cm}$ a partir da base, $3 \mathrm{~cm}$ livres (esta região ficará vulnerável à corrosão, e para isto há fita adesiva no local) e os $10 \mathrm{~cm}$ restantes com aplicação da mistura.

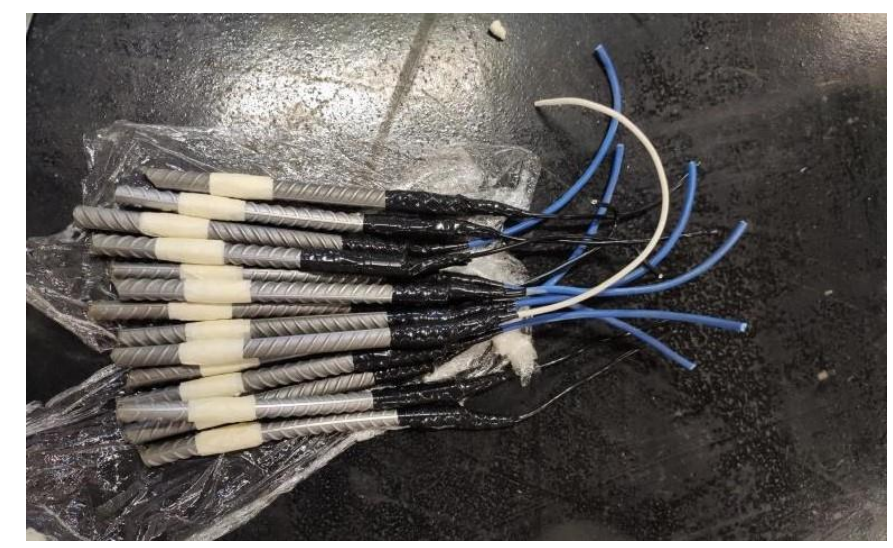

Figura 2 - Barras de aço C-50 em papeis plásticos.

O passo que procede a limpeza das barras conta com a confecção das formas de madeira as quais serão utilizadas para os moldes prismáticos de base quadrada, de dimensões em centímetro de (7x7x12) de comprimento, largura e altura em ordem respectiva. 
Foram feitos 7 moldes preenchidos com concreto convencional de alto desempenho (CAD), e identificados pelas letras (A, B, C, D, E, F e G). Também foram feitos 7 moldes preenchidos com concreto leves de alto desempenho (CLAD) e identificados pelas letras (M, N, O, P, Q, R e S). Todas as barras foram posicionadas manualmente centralizadas no molde, de modo a garantir cobrimento de $25 \mathrm{~mm}$ para efetuação coerente da leitura e o adensamento foi feito com o auxílio de agitador, no caso dos moldes preenchidos com concreto convencional, foram agitados por 1 minuto, já no concreto leve, afim de se evitar segregação das argilas fora agitado por 30 segundos, de acordo com Scobar (2016) o tempo de exposição assim como a frequência de vibração é proporcional a segregação da argila em relação a pasta. Após $24 \mathrm{~h}$, o ensaio acelerado de corrosão por meio de íons cloreto foi iniciado.

\subsection{Moldagem dos Corpos de Prova (CP) cilíndricos e respectivos traços unitários}

Além da leitura do potencial de corrosão, foram confeccionados CPs para rompimento, definindo assim a resistência que foi expressa em MPa. O mesmo traço fora utilizado tanto nas peças prismáticas quanto nos corpos de prova, que são os de conformidade com a NBR 5738 (ABNT, 2015). Para aferir resistência e realização de ensaio laboratorial, foi moldado um total de 10 corpos de prova, onde 9 foram rompidos e 1 destinado à execução do ensaio de massa específica seca (por meio deste é possível obter valores de absorção por imersão em água, índice de vazios e massa específica). Para ambos os traços, utilizou-se na mistura CP V - ARI. O. O traço unitário do concreto convencional apresentado corresponde ao apresentado pela tabela 1:

\begin{tabular}{c|c} 
Tabela $1-$ Traço unitário do concreto convencional. \\
\hline \multicolumn{2}{c}{ Concreto Convencional } \\
\hline Agregados & Traço \\
\hline Cimento & 1,00 \\
\hline Sílica ativa & 0,10 \\
\hline Areia fina & 1,28 \\
\hline Brita 0 & 0,60 \\
\hline Brita 1 & 0,80 \\
\hline Superplastificante (Tecflow) & 0,019 \\
\hline Água/Cimento & 0,045 \\
\hline
\end{tabular}

Após desmoldados os CPs, foram levados para cura úmida, onde permanecerem até o rompimento nos respectivos dias 7, 14, 21 e 28. A figura 4, corresponde ao concreto convencional em prensa hidráulica após 7 dias passados de cura.

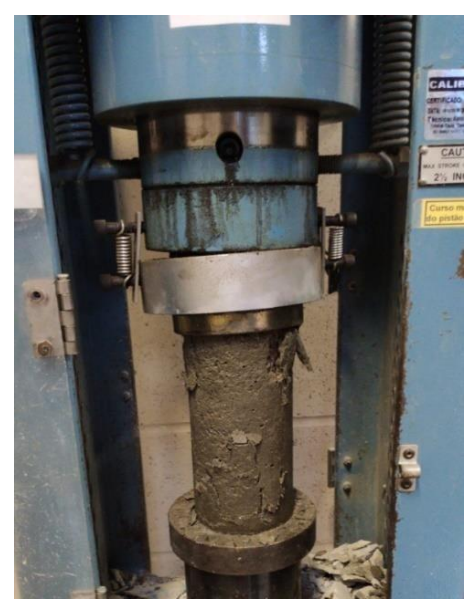

Figura 4 - Corpo de prova de concreto convencional rompido.

O traço unitário do concreto leve corresponde ao apresentado pela tabela 2: 


\section{СВРAT 2020

Tabela 2 - Traço unitário do concreto leve.

\begin{tabular}{c|c}
\hline \multicolumn{2}{c}{ Concreto Leve } \\
\hline Agregados & Traço \\
\hline Cimento & 1,00 \\
\hline Sílica ativa & 0,10 \\
\hline Areia fina & 1,28 \\
\hline Argila 0500 & 0,23 \\
\hline Argila 1506 & 0,37 \\
\hline Brita 1 & 0,80 \\
\hline Superplastificante (Tecflow) & 0,019 \\
\hline Água/Cimento & 0,045 \\
\hline
\end{tabular}

Após os 7 dias passados de cura, houve o rompimento do CP que foi registrado e apresentado na figura 5.

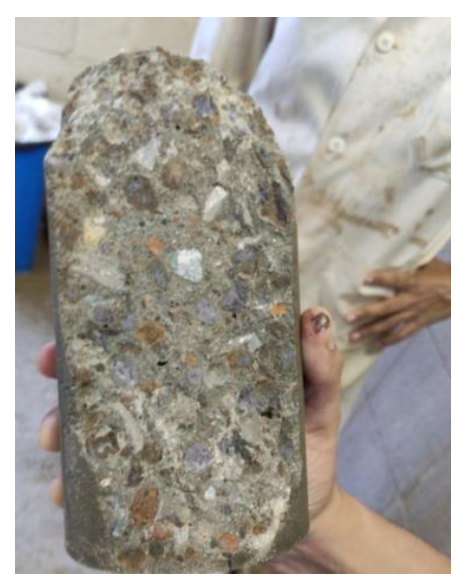

Figura 5 - Corpo de prova de concreto leve após ser rompido em prensa hidráulica.

\subsection{Modo de execução e equipamentos para Leitura de Potencial de Corrosão}

A leitura é feita por meio de um dispositivo de meia célula de cobre - sulfato de cobre, conforme ASTM C876 (1999). Composto por mangueira rígida acoplada de material plástico transparente, haste de cobre de $6 \mathrm{~mm}$ de diâmetro em seu interior, a qual armazena solução saturada de água destilada e sulfato de cobre, de modo que o excesso deste fique depositado ao fundo do dispositivo de leitura. Ainda sobre a estrutura deste, uma de suas extremidades conta com ponta porosa feita de madeira para garantir que sempre fique úmida e auxiliada por esponja, de modo a apresentar resultados precisos. A outra extremidade é fechada com tampão feito de modo que a haste transpasse este para que por meio do uso de voltímetro, seja registrada a diferença de potencial elétrico entre a barra de aço e os fios de cobre desencapados e anteriormente acoplados à barra. Sendo assim, tem-se um sistema fechado, e demonstrado pela figura 3.

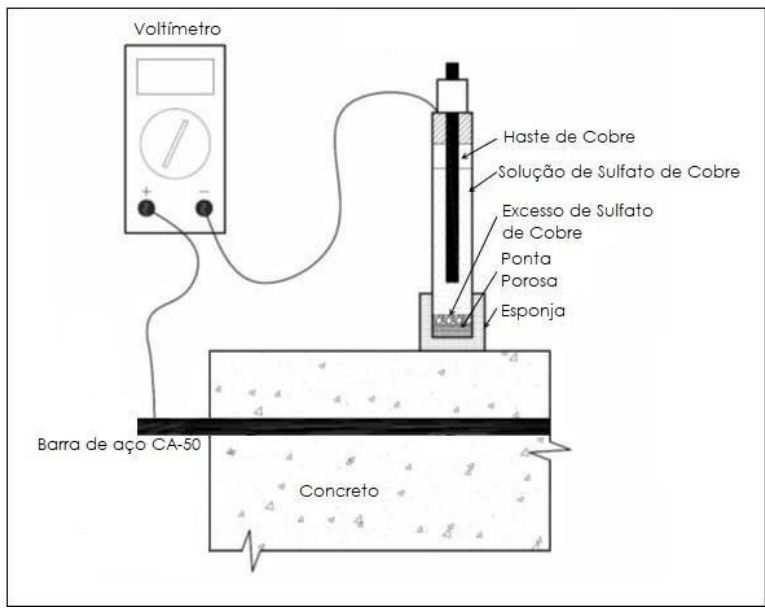

Figura 3 - Dispositivo de meia célula de cobre - Sulfato de cobre. Adaptado de ASTM C876 (1999). 
Para que erros experimentais sejam evitados, as peças prismáticas de concreto foram lavadas com água corrente e detergente neutro antes de cada leitura, de modo a garantir resultados mais precisos e para um resultado ainda mais apurado, as aferições foram feitas 2 vezes por peça estabelecendo assim análise qualitativa, e tendo em conta probabilidade de corrosão conforme ASTM C876 (1999) e exposta em tabela que se segue.

Tabela 3 - Probabilidade de corrosão, conforme ASTM C876(1999).

\begin{tabular}{c|c}
\hline \multicolumn{2}{c}{ Probabilidade De Corosão } \\
\hline Valor Aferido $(\mathrm{mV})$ & Probabilidade De Corrosão \\
\hline Maior que -200 & Menor que $10 \%$ \\
\hline Entre -200 e -350 & Incerto \\
\hline Menor que -350 & Maior que $90 \%$ \\
\hline
\end{tabular}

\subsection{Corrosão por ação de íons cloreto - Ensaio acelerado}

O processo para representação desta corrosão baseia-se em ciclos de umedecimento e secagem. Este procedimento é de ampla difusão no ramo, tendo sido reproduzido por Cabral (2000) e deste modo, apresenta resultados valorosos para a área e por conseguinte, segue breve resumo a respeito do procedimento e métodos utilizados.

Após 24h, as peças prismáticas foram desmoldadas e assim foi feita a primeira leitura no equipamento de potencial de corrosão. Com isso, as peças foram submetidas a ciclos de umedecimento e foram levadas à solução de $\mathrm{NaCl}$, por 3 dias e em seguida levadas para estufa por 4 dias a $60^{\circ} \mathrm{C}$ (para servir como catalisador das reações entre água, íons cloreto e oxigênio). Ao final deste processo, repetiu-se o ciclo.

Afim de se obter ambiente similar ao de maresia, a concentração correspondente de sal foi de 3,5\% (35g/Kg de água) de acordo com dados da Aquarius (NASA,2015).

O ensaio de potencial de corrosão baseia-se na norma técnica americana ASTM C876 (1999) com uso da meia célula de cobre Sulfato de cobre. A primeira leitura do potencial de corrosão foi executada após o desmolde, logo antes do primeiro ciclo ser iniciado e após cada intervalo de acordo com tabela a seguir.

Tabela 4 - Ciclos do ensaio acelerado de corrosão por ação de íons cloreto.

\begin{tabular}{c|c|c}
\hline \multicolumn{3}{c}{ Ciclo de Umedecimento e Secagem - Leitura Inicial 25/10/2019 } \\
\hline & Umidecimento & Secagem \\
\hline $1^{\circ}$ Ciclo & $25 / 10-28 / 10$ & $28 / 10-01 / 11$ \\
\hline $2^{\circ}$ Ciclo & $01 / 11-04 / 11$ & $04 / 11-08 / 11$ \\
\hline $3^{\circ}$ Ciclo & $08 / 11-11 / 11$ & $11 / 11-15 / 11$ \\
\hline
\end{tabular}

Ao fim dos ciclos, houve o rompimento das peças prismáticas de concreto e feita devida averiguação do estado de corrosão do aço que ficou exposto, simulando os efeitos causados em estruturas de concreto armado quando expostas a ambientes agressivos.

\subsection{Absorção, índice de vazios, massa específica seca e fator de eficiência}

Estes ensaios são regidos pela NBR 9778 (ABNT, 2009), que apresenta equação para cálculo da absorção, índice de vazio e da massa específica seca. A equação 1 corresponde a absorção de água:

$$
\left(\frac{\text { Msat - Ms }}{M s}\right) * 100
$$

Onde:

Msat - Massa do corpo-de-prova saturado;

Ms - Massa do corpo-de-prova seco em estufa.

O índice de vázios é a relação entre os volumes de poros e o volume total. Esta é expressa pela seguinte fórmula:

$$
\left(\frac{\text { Msat }-\mathrm{Ms}}{\text { Msat - Mi }}\right) * 100
$$


Onde:

Msat - Massa do corpo-de-prova saturado;

Ms - Massa do corpo-de-prova seco em estufa;

Mi - Massa do corpo-de-prova saturado, imerso em água.

Por fim, tem-se a fórmula da massa específica seca, definida pela seguinte equação:

$$
\left(\frac{\mathrm{Ms}}{\text { Msat - Mi }}\right)\left(\frac{\mathrm{kg}}{\mathrm{m}^{3}}\right)
$$

Onde:

Ms - Massa do corpo-de-prova seco em estufa; Msat - Massa do corpo-de-prova saturado;

Mi - Massa do corpo-de-prova saturado, imerso em água.

O resultado apresentado pela massa específica seca é de suma importância para o cálculo de fator de eficiência o qual define se o concreto trabalhado é de alto desempenho, e para tanto, segue a fórmula para cálculo deste:

$$
\frac{\mathrm{Fc}}{\gamma}\left(\mathrm{Mpa} * \frac{\mathrm{dm}^{3}}{\mathrm{~kg}}\right)
$$

Onde:

Fc-Resistência à compressão;

$\gamma$ - Massa específica seca.

Assim sendo, o ensaio de massa específica seca visa classificar o concreto em convencional e leve, de acordo com NBR 6118 (ABNT, 2014), onde valores entre $2000 \mathrm{~kg} / \mathrm{m}^{3}$ a $2800 \mathrm{~kg} / \mathrm{m}^{3}$ são identificados como convencionais e valores abaixo de 2000 $\mathrm{kg} / \mathrm{m}^{3}$ são definidos concretos leves.

\section{ANÁLISE DOS RESULTADOS}

Após a execução dos procedimentos conforme descrito na metodologia, foram moldados, conforme descrito no subitem 2.4 , corpos de prova cilindrícos para obtenção dos valores de resistência à compressão para cada traço, CAD e CLAD, nos respectivos dias de idade, 7, 14, 21 e 28. A tabela 5 apresenta os valores de resistência à compressão obtidos para o traço de CAD e CLAD para cada dia de idade em Mega Pascal (MPa). O gráfico 1 apresenta, também, os valores de resistência a compressão dos CP's de CAD e CLAD.

Tabela 5 - Resistência a Compressão dos CP's de CAD

\begin{tabular}{c|c|c}
\hline \multirow{2}{*}{ Dias } & \multicolumn{2}{|c}{ Resistência a Compressão (MPa) } \\
\cline { 2 - 3 } & CAD & CLAD \\
\hline 7 & 33,49 & 29,85 \\
\hline 14 & 41,23 & 35,62 \\
\hline 21 & 48,25 & 43,96 \\
\hline 28 & 51,36 & 46,12 \\
\hline
\end{tabular}




\section{CBPAT 2020

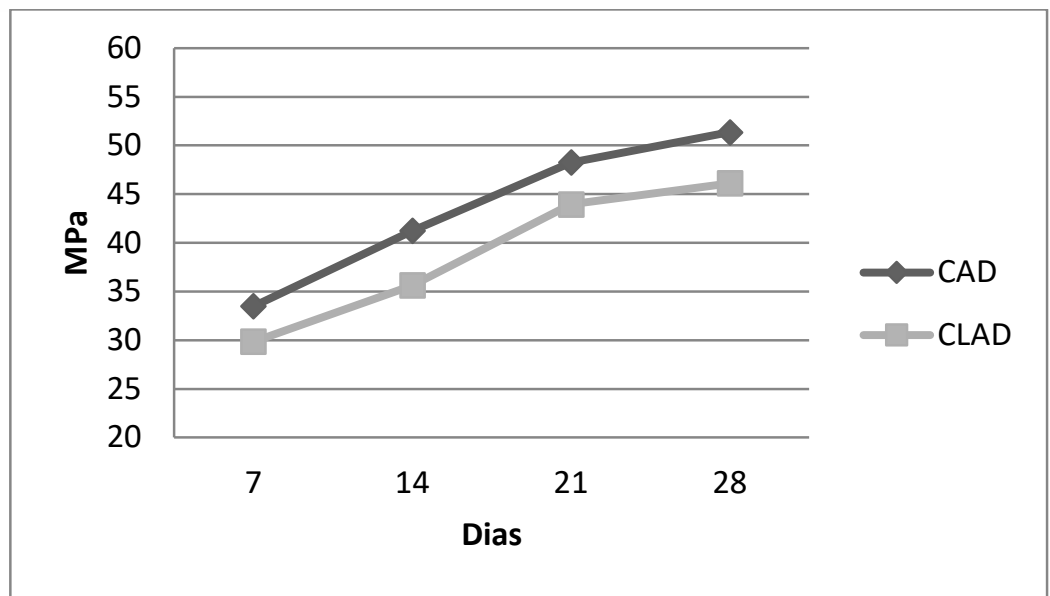

Em seguida foi executado o ensaio para a determinação de massa específica, índice de vazios e absorção de água, executado conforme a NBR 9778 (ABNT, 2009). Após a realização do procedimento, conforme o subitem 2.5 e as equações 1,2 e 3 obteve-se os resultados, respectivamente, para absorção de água, índice de vazios e massa específica seca para cada CP e seu respectivo traço. A tabela 6 apresenta os valores obtidos para absorção de água de cada $\mathrm{CP}$, índice de vazios de cada $\mathrm{CP}$ e massa específica seca para cada um.

Tabela 6 - Absorção de água para cada CP em porcentagem

\begin{tabular}{c|c|c|c}
\hline \multicolumn{2}{c|}{ Corpo de Prova CAD } & \multicolumn{2}{c}{ Corpo de Prova CLAD } \\
\hline Absorção de água $(\%)$ & 3,84 & Absorção de água $(\%)$ & 3,13 \\
\hline Índice de vazios $(\%)$ & 8,64 & Índice de vazios $(\%)$ & 5,68 \\
\hline Massa específica seca $\left(\mathrm{g} / \mathrm{cm}^{3}\right)$ & 2,25 & Massa específica seca $\left(\mathrm{g} / \mathrm{cm}^{3}\right)$ & 1,82 \\
\hline Massa específica seca $\left(\mathrm{kg} / \mathrm{m}^{3}\right)$ & 2248,17 & Massa específica seca $\left(\mathrm{kg} / \mathrm{m}^{3}\right)$ & 1817,06 \\
\hline
\end{tabular}

Notou-se que os CP's moldados com o traço de CLAD obtiveram valores, relativamente, mais satisfatórios quando comparado ao CAD, obtendo uma absorção de água, índice de vazios e massa específica seca menor do que seu concorrente. Destaca-se, entre outros fatores, que a menor absorção de água pelo concreto reduz, também, a penetração de íons cloretos presente na solução, já que, o corpo de prova armazenará menos água em seus espaços vazios, que também correspondem a uma porcentagem menor no CLAD do que no CAD, e portanto reduz a iminência de sofrer com as possíveis penetrações de íons cloretos em seu interior, quando comparado com o concreto convencional.

Após isto, foram moldadas peças com o mesmo traço de concreto convencional de alto desempenho (CAD) e de concreto leve de alto desempenho (CLAD). Foram feitas peças prismáticas de base quadrada de $7 \mathrm{~cm}$ de lado, com $14 \mathrm{~cm}$ de altura, sendo 3 peças para cada traço. As peças de CAD foram nomeadas de A, D e B, e as moldadas com CLAD foram nomeadas de $\mathrm{N}, \mathrm{O}$ e $\mathrm{Q}$. Todas as leituras realizadas nas peças foram realizadas nas mesmas faces, afim de garantir que não houvesse diferença entre $\mathrm{o}$ cobrimento entre cada leitura, que poderia interferir nos resultados obtidos.

As tabelas 7 e 8 apresentam as respectivas leituras para as peças moldadas com concreto convencional de alto desempenho (CAD) e leve de alto desempenho (CLAD) nos respectivos ciclos apresentados na tabela 1.

Tabela 7 - Leituras peças de CAD em $\mathrm{mV}$

\begin{tabular}{c|c|c|c|c|c}
\hline & $\begin{array}{c}\text { Leitura Após } \\
\text { Desforma }\end{array}$ & $\begin{array}{c}1^{\mathrm{a}} \\
\text { Leitura }\end{array}$ & $\begin{array}{c}2^{\mathrm{a}} \\
\text { Leitura }\end{array}$ & $\begin{array}{c}3^{\mathrm{a}} \\
\text { Leitura }\end{array}$ & $\begin{array}{c}4^{\mathrm{a}} \\
\text { Leitura }\end{array}$ \\
\hline A & -168 & -361 & -386 & -432 & -524 \\
\hline B & -260 & -356 & -358 & -462 & -533 \\
\hline D & -192 & -302 & -352 & -325 & -490 \\
\hline
\end{tabular}

Tabela 8 - Leituras peças de CLAD em $\mathrm{mV}$

\begin{tabular}{c|c|c|c|c|c}
\hline & $\begin{array}{c}\text { Leitura Após } \\
\text { Desforma }\end{array}$ & $\begin{array}{c}1^{\mathrm{a}} \\
\text { Leitura }\end{array}$ & $\begin{array}{c}2^{\mathrm{a}} \\
\text { Leitura }\end{array}$ & $\begin{array}{c}3^{\mathrm{a}} \\
\text { Leitura }\end{array}$ & $\begin{array}{c}4^{\mathrm{a}} \\
\text { Leitura }\end{array}$ \\
\hline $\mathrm{N}$ & -301 & -326 & -379 & -444 & -449 \\
\hline $\mathrm{O}$ & -299 & -337 & -462 & -491 & -510 \\
\hline $\mathrm{Q}$ & -182 & -202 & -293 & -315 & -419 \\
\hline
\end{tabular}


Observa-se que os valores para potencial de corrosão de todas as peças de todos os traços aumentam, conforme são realizadas as leituras e estas expostas ao ambiente de $\mathrm{NaCl}$, fato que pode ser explicado, justamente, devido a penetração de íons cloreto na estrutura interna do concreto, até chegar à armadura.

Constatou-se que o concreto leve de alto desempenho e o concreto convencional obtiveram resultados extremamente próximos nas leituras de potencial de corrosão, não podendo-se afirmar, portanto, qual concreto obteve um desempenho efetivamente superior ao seu concorrente. Ainda que, todas as peças de CLAD só tenham obtidos valores menores do que $-350 \mathrm{mV}$, onde, de acordo com a ASTM C876 (1999), possui $95 \%$ de probabilidade de já terem sofrido corrosão, na $4^{\text {a }}$ leitura, enquanto todas as peças de CAD apresentaram valores inferiores a -350 na $2^{\mathrm{a}}$ leitura, não é possível, sem uma análise estatística, afirmar que as peças de CLAD levaram menos tempo para sofrerem com a penetração de íons cloretos, quando comparadas com as peças de $\mathrm{CAD}$, pois os valores para os dois traços foram extremamente próximos.

Gráfico 2 - Potencial de corrosão para cada CP na respectiva leitura

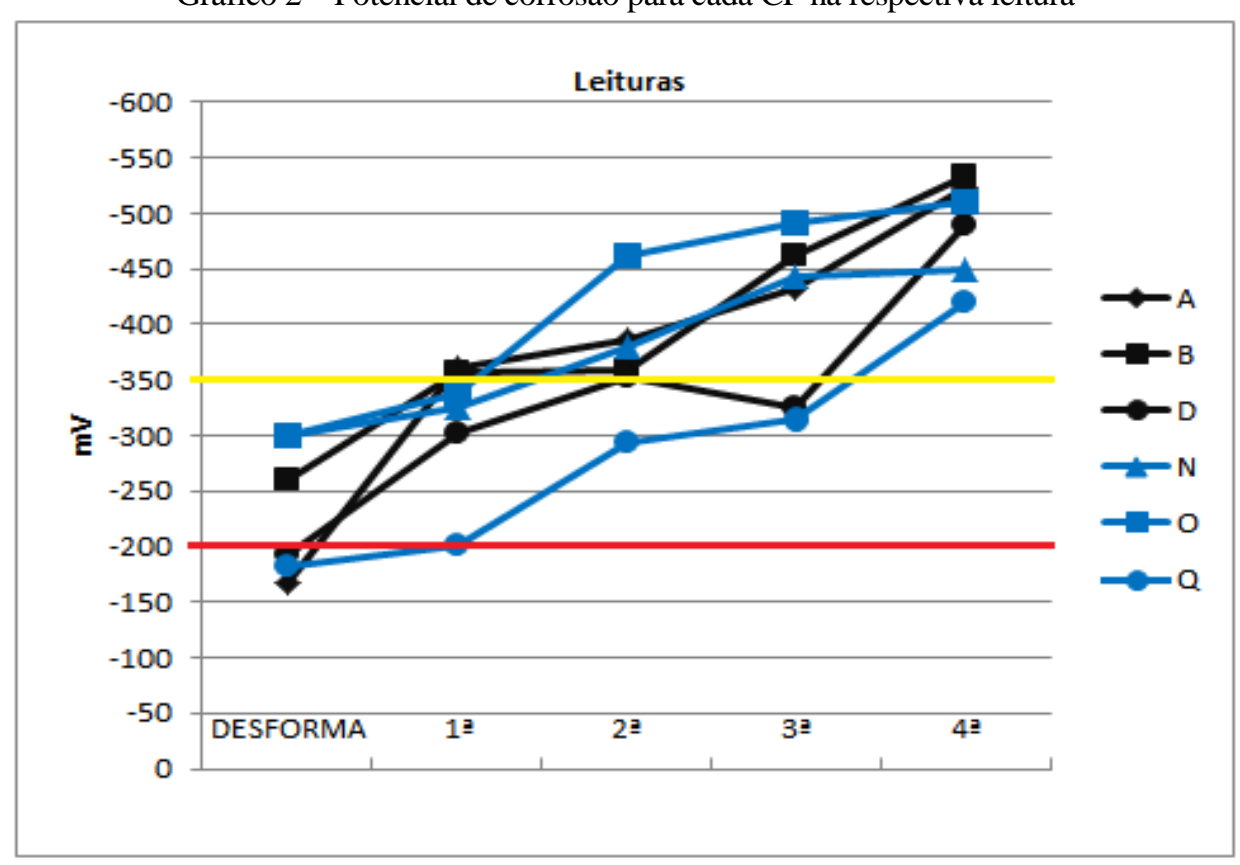

O gráfico 2 apresenta os valores de potencial de corrosão em mV, nos respectivos dias de leitura. A linha vermelha, conforme descreve a ASTM C876 (1999), representa o limite inferior, onde abaixo deste, a probabilidade de ocorrer a corrosão limita-se a $5 \%$, ou seja, não ocorreu corrosão, já a linha amarela indica o limite superior, onde após esta a probabilidade de corrosão é de 95\% e indica iminente corrosão, e entre os limites não é possível afirmar se houve ou não corrosão nas barras. Verifica-se que na última leitura, todos os CP's submetidos ao ambiente com $\mathrm{NaCl}$ sofreram corrosão.

Afim da verificação da corrosão nas barras, as peças prismáticas foram quebradas e as barras retiradas do concreto. A imagem abaixo mostra 3 barras de após o rompimento das peças, nota-se evidente corrosão em todas.

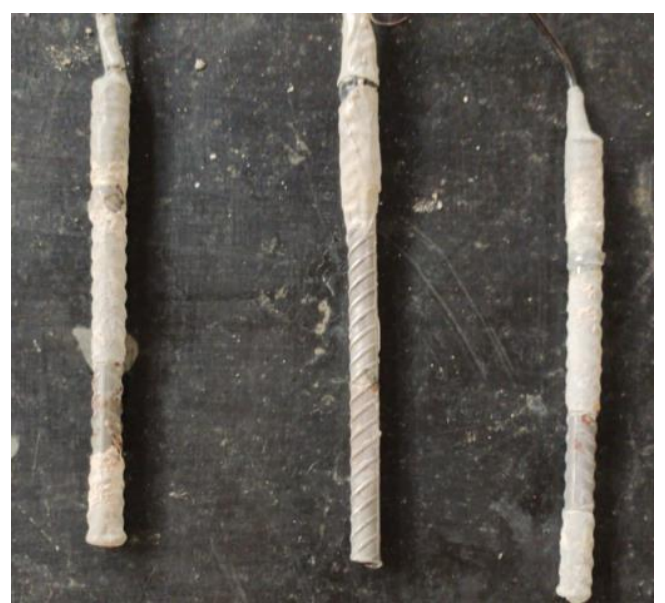

Figura 6 - Barras de CA-50 de CLAD corroídas 
Por último obteve-se o valor do fator de eficiência para o concreto com agregado leve, para respectiva classificação, ou não, deste como concreto leve de alto desempenho. De acordo com Spitzner e Armelin (1994) concretos com fator de eficiência acima de $25 \mathrm{MPa} . \mathrm{dm}^{3} / \mathrm{kg}$ podem ser considerados concretos leves de alto desempenho. Utilizando a equação 4, obtve-se o valor do fator de eficiência para o traço de concreto leve elaborado pelos autores, podendo, portanto, classificá-lo como CLAD. O valor do fator de eficiência é mostrado na tabela 9, abaixo.

Tabela 9 - Fator de eficiência CLAD

\begin{tabular}{l|l}
\hline \multicolumn{2}{c}{ CLAD } \\
\hline Fator de Eficiência (Mpa.dm $3 / \mathrm{kg})$ & 25,38167 \\
\hline
\end{tabular}

\section{CONCLUSÃO}

É consenso que todo produto para ser inserido em um mercado altamente competitivo deve proporcionar bons desempenhos do ponto de vista mecânico e de durabilidade, ser ecologicamente correto, principalmente frente ao desenvolvimento sustentável e à disponibilidade de recursos naturais e finalmente ser economicamente viável e o concreto de alto desempenho se encaixa nos padrões dos aspectos de resistência e durabilidade proporcionados aos concretos e do aspecto ecológico, como apresentado neste estudo.

Este estudo apresenta um tipo particular de concreto, com características e propriedades diferenciadas em função da utilização conjunta de cimento CP V - ARI, sílica ativa, superplastificante (tec-flow) e agregados leves (argila expandida). Este concreto, denominado concreto leve de alto desempenho (CLAD) encontra aplicação específica no setor da construção civil, na produção de elementos pré-fabricados, tais como painéis estruturais e de vedação, telhas e vigas.

De acordo com a análise dos resultados, observou-se que o traço de CLAD e CAD obtiveram desempenhos extremamente próximos no estudo de potencial de corrosão, não sendo possível, portanto, uma afirmação de qual traço obteve um desempenho mais satisfatório. Entretanto o traço de CLAD obteve um desempenho superior ao de CAD nos demais parâmetros, como absorção de água, índices de vazios, massa específica seca e, principalmente, um fator de eficiência adequado. Portanto, ainda que no parâmetro potencial de corrosão não seja possível dinstinguí-los por desempenho, nos demais parâmetros o CLAD obteve uma grande vantagem, revelando, então, motivos pelos quais revela aplicação de CLAD em situações práticas da engenharia civil.

No estudo experimental, observou-se que os concretos leves de alto desempenho no traço utilizado em questão, são adequados para serem utilizados em situações onde deseja-se reduzir a massa específica da estrutura, o índice de vazios ou a absorção de água pelo concreto, como ambientes litorâneos, podendo vir a substituir o concreto convencional, haja vista o uso de agregados leves como a argila expandida em sua composição que de acordo com Rossignolo (2003) apesar de apresentar valores acima de $50 \%$ de porosidade, tem baixa permeabilidade por não apresentar interligação entre seus poros, visto que a durabilidade depende essencialmente da permeabilidade do material. Outro ponto chave para maior durabilidade deste tipo de concreto é a utilização de sílica ativa que conforme estudos também realizados por Rossignolo (2003) há uma forte relação entre a espessura e qualidade da zona de transição agregado-matriz e as propriedades mecânicas e a durabilidade dos concretos.

Dentre os pontos que se destacam para a escolha do concreto leve de alto desempenho, destaca-se, através da análise dos resultados apresentados no presente trabalho, a redução da massa específica; ao excelente desempenho das propriedades relacionadas à resistência mecânica; menor índice de vazios e absorção de água do concreto, aumentando a durabilidade da estrutura. Porém, para que possa ser utilizado devem ser feitos estudos preliminares, pois o mesmo também apresenta suas desvantagens perante o concreto convencional de alta resistência, possuindo um valor menor de resistência à compressão axial em todos os dias de idade.

O levantamento bibliográfico confirma a importância dos pontos abordados neste trabalho, evidenciando que o assunto durabilidade das estruturas de concreto ocupa lugar de destaque no campo da tecnologia do concreto. Pelos artigos consultados pode-se observar que a durabilidade, do ponto de vista do ataque de cloretos, é assunto muito pesquisado no Brasil e no exterior, devendo ser bastante explorado em trabalhos futuros. 


\section{REFERÊNCIAS}

AÏTCIN, P.C. Concretes of yesterday, today and tomorrow. In: CONGRESSO BRASILEIRO DO CONCRETO, 41. Salvador, 1999. Anais.

ALDUAIJ, A. et al. Lightweight concrete in hot coastal areas. Cement and Concrete Composites, n.21, p.453-458, 1999.

ALMEIDA, I.R. Superplastificantes, microssílica e durabilidade dos concretos. Revista Téchne, v.5, p.30-33, 1996.

ARMELIN, H.S.; LIMA, M.G.; SELMO, S.M.S. Alta resistência com argila expandida. Revista Ibracon, n.09, p.42- 47, 1994.

ASSOCIAÇÃO BRASILEIRA DE NORMAS TÉCNICAS. NBR 5738: Concreto - Procedimento para moldagem e cura de corpos de prova. Rio de Janeiro, 2015.

ASSOCIAÇÃO BRASILEIRA DE NORMAS TÉCNICAS. NBR 6118: Projeto de estruturas de concreto Procedimento. Rio de Janeiro, 2014.

ASSOCIAÇÃO BRASILEIRA DE NORMAS TÉCNICAS. NBR 9778: Argamassa e concreto endurecidos Determinação da absorção de água, índice de vazios e massa específica. Rio de Janeiro, 2009.

ASTM G1-90: Standard practice for preparing, cleaning and evaluating test speciments. Philadelphia, 199. (Reapproved 1994)

ASTM. AMERICAN SOCIETY FOR TESTING AND MATERIALS. ASTM C 876: Standard test method for halfcell potentials of uncoated reinforced steel in concrete - (1999 reapproved 2009). Annual Book of ASTM Standard, 2009.

BERNER, D.E. High ductility, high strength lightweight aggregate concrete. In: ACI SYMPOSIUM ON PERFORMANCE OF STRUCTURAL LIGHTWEIGHT CONCRETE. Dallas, Texas, 1991. Proceedings.

CABRAL, A. E. B. Avaliação da eficiência de sistema de reparo no combate à iniciação e à propagação da corrosão do aço induzida por cloretos. Porto Alegre-RS, 2000. 187p. Dissertação (Mestrado). Universidade Federal do Rio Grande do Sul.

FAGERLUND, G. Studier av fasgränser - Cementpasta i cementbruk och betong. Report 29, Inst. for Byggnadsteknik, Tekniska Högskolen, Lund, 1972.

HAQUE, M.N.; AL-KHAIAT, H. Strength and durability of lightweight concrete in hot marine exposure conditions. Materials Structures, v.32, p.533-538, 1999.

HELENE, P.R.L. Concreto de alto desempenho: o melhor está por vir. Revista Cimento Hoje, n.20, 1999.

HOLM, T.A.; BREMNER, T.W. (1994). High Strength Lightweight Aggregate Concrete. In: High performance concrete: properties and aplications. Ed. SHAH, S.P. and AHAMAD. S.H.Great Britain, McGraw-Hill, pp. 341- 374.

HOLM, T.A.; BREMNER, T.W.; NEWMAN, J.B. Lightweight aggregate concrete subject to severe weathering. Concrete International, v.6, n.6, p.49-54, 1984.

IKEDA, S. Recent developments in LWAC in Japan. In: INTERNATIONAL SYMPOSIUM ON STRUCTURAL LIGHTWEIGHT AGGREGATE CONCRETE, 2. Kristiansand, Norway, 2000. Proceedings, p.16-26.

KUMAYAMA, Rosemarie. Estudo da viabilidade do emprego do pó de mármore para produção de concreto autoadensável e substituição parcial dos agregados por pérolas de poliestireno expandido (EPS). 2014. $111 \mathrm{f}$. Dissertação (mestrado) - Universidade Estadual Paulista Júlio de Mesquita Filho, Faculdade de Engenharia de Ilha Solteira, 2014. Disponível em: 〈http://hdl.handle.net/11449/111145>. 
MEHTA, K.; MONTEIRO, J.M. Concreto: Estrutura, Propriedades e Materiais. PINI. São Paulo, 1994. MORENO, J. Lightweight concrete ductility. Concrete International, v.8, n.11, p.15-18, 1986.

NASA, Aquarius. Sea Surface Salinity from Space. 2015. Disponível em: <https:// https://aquarius.oceansciences.org/cgi/gal_salinity.cgi>. Acesso em: 7 nov. 2019.

OHAMA, Y. Polymer-based Admixtures. Cement and Concrete Composites, n.20, p.189-212, 1998.

PAULON, V.A. Interface entre a pasta de cimento e agregado. In: CONGRESSO BRASILEIRO DO CONCRETO, 37. Goiânia, 1996. Anais, v.1, p.479-492.

ROSSIGNOLO, J. A. Concreto leve estrutural: produção, propriedades, microestrutura e aplicações. São Paulo: PINI, 2009.

ROSSIGNOLO, J.A.; PAULON, V.A.; AGNESINI, M.V.C. Concreto leve de elevado desempenho. Revista Engenharia e Construção, n.56, p.24-30, 2001.

SCOBAR, Renan Luna. Concreto leve estrutural: substituição do agregado graúdo convencional por argila expandida. Orientador: Valdomiro Lubachevski Kurta. 2016. 48 p. Dissertação (Graduação em Engenharia Civil) Universidade Tecnológica Federal do Paraná - Câmpus Campo Mourão, Paraná, 2016.

SILVA, F. C. Galvanização a quente: processo por batelada, SÃO PAULO

SISEL, D.A. The state of the art abd future trends in the strutural design of high-rise buildings. In: SIMPÓSIO BRASILEIRO SOBRE EDIFÍCIOS DE CONCRETO DE GRANDE ALTURA. IBRACON. São Paulo, 2000.

SLATE, F.O.; NILSON, A.H.; MARTÍNEZ, S. Mechanical Properties of High-Strength Lightweight Concrete. ACI Materials Journal, v.83, n.4, p.606-613, 1986.

SPITZNER, J. High-Strength LWA Concrete. In: High-Strength Concrete. RILEM Cap.II - Aggregates. 1994.

VIEIRA, M.G. Betões de elevado desempenho com agregados leves - Durabilidade e microstrutura. Lisboa, Portugal, 2000. Dissertação (mestrado) - Instituto Superior Técnico da Universidade Técnica de Lisboa.

WASSERMAN, R.; BENTUR, A. Interfacial interactions in lightweight aggregate concretes and their influence on the concrete strength. Cement and Concrete Composites, v.18, p.67-76, 1996.

ZHANG, M.H.; GJ $\phi R V$, O.E. Mechanical properties of high-strength lightweight concrete. ACI Materials Journal, v.88, n.3, p.240-247, 1991.

ZHANG, M.H.; GJ $\phi$ RV, O.E. Microestructure of the interfacial zone between lightweight concrete and cement paste. Cement and Concrete Research, v.20, p.610-618, 1990.

ZHANG, M.H.; GJфRV, O.E. Pozzolanic reactivity of lightweight aggregates. Cement and Concrete Research, v.20, p.884-90, 1990. 